\title{
La necesaria rehabilitación del sistema representativo en las propuestas de reforma democrática*
}

\section{The necessary rehabilitation of the representative system in democratic reform proposals}

\author{
Pedro Jesús PÉREZ Zafrilla
}

Universidad de Valencia

RESUMEN. En los debates sobre la democracia deliberativa existe una idea generalizada de que los proponentes de esta corriente apuestan por una participación directa de los ciudadanos en los asuntos públicos y una transformación radical de nuestros sistemas políticos actuales, basados en la representación. Sin embargo, en este trabajo pretendo demostrar que esta visión no es del todo acertada, y que son una minoría los que defienden la participación directa. Por el contrario, la mayoría de autores reconocen la necesidad de un sistema representativo, aunque basado en premisas diferentes del sistema liberal. Frente a un modelo que fomenta el autointerés de los ciudadanos, la democracia deliberativa apuesta por la promoción de una ciudadanía responsable y comprometida con el bien común.

Palabras clave: Democracia deliberativa, liberalismo, participación directa, representación, preferencias, bien común, valor epistémico, democracia radical.

\section{Introducción}

Desde finales de los años sesenta y comienzos de los setenta se ha venido constatando en el ámbito político un continuo descenso de la participación política de la
ABstract. In the debates on deliberative democracy it's a common idea that the defenders of this theory argue for the direct participation of the citizens in the political issues and for the transformation of our current representative devices. However, in this work I argue that this conception is misguided, and that it's the minority who defends the direct participation. The majority of the writers acknowledges the necessity of a representative device, although based on different premises to the liberal system. The deliberative democracy supports a responsible and compromised citizenship, against the model of self interested citizenship.

Key words: Deliberative democracy, liberalism, direct participation, preferences, common good, epistemic value, radical democracy.

ciudadanía. Elementos como la menor identificación de los ciudadanos con los partidos, la pérdida de confianza en los políticos, la apatía y el aumento exponencial del absentismo en las elecciones son los aspectos más relevantes de este fenó- 
meno, cuya máxima consecuencia ha sido el progresivo distanciamiento de los ciudadanos no sólo de los partidos, sino de la política misma.

Una causa de este proceso cabe encontrarla, sin duda, en la misma lógica que ha dominado el proceso democrático liberal durante el siglo XX. No en vano, este sistema político se erige en buena medida sobre los planteamientos elaborados desde la teoría elitista de la democracia, articulada, entre otros, por Schumpeter y plasmada en el informe de Huntington, Crozier y Watanuki para la Comisión Trilateral de 1973, relativo a la crisis de la democracia. ${ }^{1}$ Desde esa línea de pensamiento de corte liberal, se defendía la necesidad de restringir la participación política de los ciudadanos y que la gestión de los asuntos públicos quedara reducida a unas élites elegidas en elecciones libres por los ciudadanos. Esta forma de limitar la actividad de los ciudadanos en la esfera pública generó, por un lado, una tendencia a la apatía y al distanciamiento respecto de la política, y por otro una incidencia en la agregación de preferencias y la promoción de los intereses egoístas, al concebir la política como una forma de conjugar intereses en conflicto.

Será como una respuesta a este modelo político liberal como nació la democracia deliberativa a comienzos de la década de 1980 de la mano de Benjamin Barber. Es cierto que un denominador común entre los proponentes de la democracia deliberativa es la crítica al sistema liberal. No obstante, contra lo que pudiera parecer, estas críticas no han llevado a la mayoría de los demócratas deliberativos a proponer una transformación radical de nuestros sistemas políticos actuales, basados en la representación. Como mostraré a lo largo de estas páginas, no resulta del todo acertado identificar la democracia deliberativa con una teoría de la democracia que apueste por una partici- pación directa de los ciudadanos y contrapuesta al sistema representativo actual al que pretenda suplantar. Por un lado, porque la democracia deliberativa es una concepción heterogénea que agrupa una diversidad de propuestas teóricas. Y por otro, porque tales propuestas no comparten, en general, ni una defensa de la democracia directa ni tampoco una visión común del sistema representativo. De este modo, el análisis del tratamiento que hacen estos autores de la participación política nos podrá ayudar no sólo a tener una comprensión mayor de esta teoría de la democracia, sino también un criterio que nos permita clasificar las distintas propuestas en este asunto.

Efectivamente, no todos los demócratas deliberativos propugnan un sistema de democracia directa. Es más, en verdad esto sólo lo defenderá una minoría. En mi opinión, para comprender mejor el modo como desde la democracia deliberativa se aborda el modo en que debe articularse la participación política de los ciudadanos, podemos dividir a los distintos autores en tres grupos distintos. Por un lado, estarían los que de hecho defienden la participación directa de los ciudadanos en la gestión de los asuntos públicos. Aquí debemos citar, por un lado, a Benjamín Barber y por otro, a unos autores agrupados en torno a la reciente idea del Empowered Participatory Governance (que podríamos traducir como «gobierno participativo empoderado»), entre los que encontramos a Archon Fung, Eric Olin Wright, o Gianpaolo Baiocchi, así como a David Crocker.

Un segundo grupo correspondería a los autores que creen conveniente un sistema representativo, pero que lo consideran como un mal menor ante la imposibilidad material de que todos los ciudadanos puedan participar directamente. Para los miembros de este grupo lo ideal sería que todos pudieran participar, pero las 
condiciones materiales de nuestras sociedades a gran escala lo impiden. De ahí que el recurso a la representación sea inevitable. Aquí encontraríamos sólo a Carlos Santiago Nino.

Por último, hay incluso demócratas deliberativos que apuestan decididamente por el sistema representativo como la forma de gobierno que mejor realiza la democracia deliberativa y rechazan, por inviable, la participación directa de los ciudadanos. Éste es curiosamente el grupo más numeroso. Forman parte de él desde Habermas a James Fishkin, pasando por Amy Gutmann y Dennis Thompson, Thomas Christiano, John Dryzek, Robert Goodin o Joshua Cohen.

Ahora bien, ¿cuál es el criterio empleado que nos permite establecer esta clasificación? A mi entender, la forma en que los distintos autores abordan el modo de participación de los ciudadanos en la democracia deliberativa depende del que es un elemento fundamental de esta teoría de la democracia: el valor epistémico otorgado a la deliberación.

\section{El valor epistémico de la deliberación}

Como hemos dicho, un aspecto característico de la democracia deliberativa lo constituye la crítica al modelo liberal, al que los autores de la democracia deliberativa identifican como una concepción «antagonista» de la democracia. ${ }^{2}$ Frente a ella surgió precisamente la democracia deliberativa. ${ }^{3}$ Ciertamente, el liberalismo constituye una teoría compleja que cuenta con diversas corrientes en su seno, como las teorías de Mill, Rawls o Dworkin. Todas ellas comparten la necesidad de que el sistema político proteja unas libertades y derechos básicos de sus ciudadanos y que, por tanto, las decisiones mayoritarias no puedan nunca violar esas garantías constitucionales. Sin embargo, aquella corriente que ha articulado la democracia liberal ha sido en realidad la heredera de la teoría elitista de la democracia. De esta forma, triunfó un sistema político centrado en el monopolio de la acción política por parte de las élites y en la agregación de intereses particulares, siendo la apatía la característica que mejor define la actividad del ciudadano medio en la esfera pública.

Frente a este sistema, la democracia deliberativa hace de la deliberación el centro de la participación democrática. Para defender el tránsito en el proceso de toma de decisiones de la agregación de votos secretos a la defensa pública de las propuestas de los ciudadanos, los autores de la democracia deliberativa enfatizarán la superioridad epistémica que posee la deliberación frente a la agregación. Según los defensores de la democracia deliberativa, el recurso a la deliberación permite llegar a decisiones mejores que la mera agregación de votos. Ello es así porque la deliberación incrementa el valor epistémico del proceso. Dicho valor epistémico se refleja en el hecho de que para estos autores, los individuos, al participar en el foro público no lo hacen sobre sus intereses particulares, sino sobre sus concepciones sobre lo que constituye la decisión más justa o correcta. En este sentido, el criterio de justicia es independiente de nuestras preferencias e intereses así como del proceso de toma de decisiones. Ésta es la denominada concepción cognitiva del voto, que diferenciará claramente a la democracia deliberativa de la liberal. De hecho, consiste en el elemento esencial, no sólo del giro epistémico de la democracia deliberativa, sino de la misma definición de esta teoría de la democracia. ${ }^{4}$

Para esta teoría, los votos son expresión de juicios sobre la opción que mejor promueva el bien común según ese ideal independiente, y no de preferencias personales. ${ }^{5}$ Esto diferencia la democracia deliberativa de la pluralista o elitista, re- 
presentada por autores como Schumpeter, y explica la fuerte oposición que ejercerán los pioneros de la democracia deliberativa, como Barber o Mansbridge, frente al modelo liberal heredado de los planteamientos elitistas. Para los elitistas, los ciudadanos basan su acción política en la elección de aquella alternativa política que mejor satisfaga sus preferencias personales, ya que son incapaces de poder perseguir y determinar una voluntad general, ante la limitación de su conocimiento. ${ }^{6}$ Será precisamente a partir de esta concepción de la democracia como Barber erija su idea de «democracia blanda» como caracterización del modelo liberal, basado en las preferencias individuales y no en el compromiso de los ciudadanos en el bien común, propio de la «democracia fuerte» que dará título a su obra de 1984 y constituirá una de las primeras y más populares caracterizaciones de la democracia deliberativa. De hecho, en buena medida será la obra de Barber Democracia fuerte la que, por un lado, trace los ejes a los que se ceñirán las propuestas posteriores de democracia deliberativa, y por otro, siembre la fama que adquirirá esta teoría de la democracia como opuesta al liberalismo.

Así pues, frente al modelo liberal, para los teóricos de la democracia deliberativa, el ciudadano, a la hora de participar en política, no lo hace para satisfacer preferencias fijas y predeterminadas, sino sobre el compromiso de lograr la mejor decisión. Para ello no basa su voto en la satisfacción de sus preferencias, sino en juicios reflexivos sobre la política más adecuada. De ahí el giro epistémico de la democracia deliberativa. Gracias a ello, la participación asentada en los juicios reflexivos lleva a los ciudadanos a transformar en el marco de un proceso deliberativo sus preferencias e intereses egoístas en un mayor compromiso con el todo social. En este sentido, Henry Richardson va más allá y afirma explícitamente que parte de las categorías de intenciones y voluntad y no de preferencias o creencias en su teoría de la democracia deliberativa. ${ }^{7}$ Esta concepción cognitiva proporciona una base moral y epistémica a la participación democrática en las sociedades complejas. ${ }^{8}$

Junto a esta concepción epistémica del voto, existen otros cinco argumentos que apoyan la superioridad epistémica de la deliberación frente al mero regateo de intereses egoístas como proceso de toma de decisiones políticas:

a) Incrementa el conocimiento disponible. La deliberación potencia el intercambio de información sobre los intereses y necesidades de los afectados por las decisiones, por lo que aumenta el conocimiento disponible para la toma de decisiones. ${ }^{9}$

b) La deliberación permite la expresión de los intereses y preferencias de los individuos. Esto puede ayudar a transformar esas preferencias en otras más receptivas al bien común al conocer los intereses y preferencias de los otros.

c) Permite la detección de errores de información que tienen los individuos sobre el mundo y sobre sus propias preferencias.

d) Será el proceso deliberativo, mediante la criba de las razones aceptables, el que permita a los ciudadanos vencer los prejuicios que les llevan a favorecer sus propias concepciones e infravalorar la visión de los otros. Ayuda a eliminar las facciones y grupos de interés, generando una base de decisión más imparcial.

e) Finalmente, la deliberación dificulta la manipulación de la información, idea que será discutida por los teóricos de la diferencia.

Ahora bien, a pesar de que los proponentes de la democracia deliberativa de- 
fienden la superioridad de la deliberación sobre la negociación como método para la toma de decisiones políticas por las razones señaladas, sin embargo, los distintos autores divergen en el lugar donde situar ese valor epistémico que posee la deliberación. Para unos, como Benjamin Barber, Carlos Santiago Nino, o los proponentes del denominado «gobierno participativo empoderado» ${ }^{10}$ como Archon Fung, dicho valor reside en la participación: cuanta más gente participe en el debate, más puntos de vista habrá y más fácilmente se podrá obtener una decisión correcta. Para alcanzar la decisión más adecuada, el conjunto de ciudadanos debe tomar parte en el proceso de toma de decisiones. ${ }^{11}$ Este objetivo se logrará, según estos autores, mediante procedimientos de descentralización política, ya sea la democracia fuerte de Barber o los procesos de Porto Alegre y Kerala. Frente a este planteamiento, una mayoría de autores, desde Habermas a Rawls, pasando por Amy Gutmann, Thompson, Henry Richardson, Thomas Christiano o John Dryzek, se decantará por situar en la deliberación misma, en el intercambio de opiniones, y no en la participación, dicho valor epistémico. Serán éstas en realidad, como veremos, dos posturas antagónicas, lo cual nos da una muestra del carácter heterogéneo que presenta la democracia deliberativa.

En todo caso, decir que el valor epistémico reside en la participación en lugar de la deliberación no supone dejar en un segundo plano el proceso deliberativo. Como veremos a continuación, en realidad el valor epistémico reside en el proceso deliberativo mismo, y esto es algo que comparten todos los autores. ${ }^{12}$ Cuando Nino y otros autores del primer grupo enfatizan el aspecto de la participación, lo que están queriendo decir es que cuanto mayor sea el número de personas que intervengan, se podrá contar con un mayor número de detalles en el proceso deliberativo, por lo que habrá más garantías de tomar la decisión correcta. Frente a esta perspectiva, la mayoría de autores pretende focalizar el valor epistémico de la democracia en la deliberación misma. Para ellos, una decisión adoptada puede ser correcta no porque participe un mayor número de personas e intercambien información, sino si se deriva de un proceso deliberativo desarrollado bajo unas condiciones determinadas. No es el número de participantes, sino las condiciones puestas al proceso, las que aproxima la decisión a la corrección. Dichas condiciones comprenden las restricciones materiales con que cuenta todo proceso deliberativo, como son las de tiempo y espacio. Por ello, si tales condiciones resultan violadas, será imposible tomar una decisión correcta.

De esta manera, estos autores, acentuando la importancia que posee la deliberación en el proceso de toma de decisiones, comparten una preocupación común, que ya fuera señalada por los Federalistas americanos: en las sociedades actuales el gran número de habitantes y la extensión de los países hacen imposible que pueda darse un proceso deliberativo al modo como existía allá en Grecia. Por otro lado, está la constricción del tiempo. Si todos los ciudadanos de nuestras sociedades participaran en la deliberación y se diera a todos la oportunidad de intervenir en la misma, sólo podría hablar una parte de ellos y por muy poco tiempo. Así, por ejemplo, desarrollando un proceso deliberativo durante seis horas, y dejando hablar a cada persona durante sólo cinco minutos, sólo podrían intervenir setenta y dos de ellas. Pero si queremos desarrollar dicho proceso en una sociedad como la actual, está claro que la participación de todos resulta inviable. Sólo sería posible la participación de una mínima parte, por lo que no se po- 
dría cumplir el supuesto básico del otro grupo de autores: que participe el mayor número de personas posible. Si somos realistas, tal proyecto es imposible de asumir, por las restricciones señaladas de tiempo y espacio. ${ }^{13}$ Ambos elementos, el número de personas y el límite de tiempo constituyen lo que Dryzek denomina constricción de la economía deliberativa, ${ }^{14}$ y toda propuesta de deliberación aportada debe tenerla en cuenta si quiere ser factible.

Como se deduce de lo dicho hasta ahora, la referencia hecha al valor epistémico de la democracia deliberativa guarda una estrecha relación con el problema de la participación política de los ciudadanos en la democracia deliberativa. Según sea entendida, la participación política es un elemento que puede reforzar o desestabilizar dicho valor. Así, unos autores apoyan ese valor epistémico en una participación directa de los ciudadanos, mientras que otros ven esa participación directa como una rémora para el desarrollo de la deliberación, en la cual se asienta el valor epistémico de la democracia deliberativa. En consecuencia, aquellos que entiendan que la decisión correcta se consigue gracias a la participación de un mayor número de ciudadanos posible, apostarán por una participación directa de los ciudadanos en la política. En cambio, para aquellos para los que la corrección de la decisión se deba sólo al proceso deliberativo, defenderán un sistema representativo, ya que no será posible llevar a cabo de una forma fructífera la deliberación si el número de participantes es excesivo.

Como vemos, son éstos dos planteamientos antagónicos, pero ambos defendidos por miembros de la democracia deliberativa. Esto demuestra, por un lado, que la democracia deliberativa constituye una teoría más heterogénea de lo que habitualmente se piensa, y por otro, que no es una característica definitoria de esta teoría de la democracia la participación directa, como también suele afirmarse, sino más bien el logro del bien común frente a la negociación entre intereses egoístas, propio del modelo liberal de corte elitista. En este sentido, el objetivo de las siguientes páginas será desgranar la visión que se tiene de la representación desde estas distintas corrientes de la democracia deliberativa y en qué medida éstas creen más o menos posible o recomendable la participación directa de los ciudadanos. Comenzaré por aquellos que apuestan por una participación directa de los ciudadanos, para pasar a continuación a exponer las razones que llevan al resto de autores a defender la idoneidad del sistema representativo frente al directo.

\section{Los defensores de la participación directa}

Aunque pudiera parecer lo contrario, los que defienden la participación directa de los ciudadanos en la política son la excepción en la democracia deliberativa. Son, por un lado, Barber, y, por otro, los proponentes de «gobierno participativo empoderado».

Barber apuesta decididamente por la participación directa de los ciudadanos en la política. La razón la encontramos en su oposición a la democracia blanda con la idea de libertad negativa: no podemos entender la libertad como el aseguramiento de una serie de derechos individuales; esto es, el atrincheramiento del sujeto en una esfera de autorrealización que le retraiga de su participación en la política. El gran error de la libertad de los modernos es pagar a unos representantes para que se ocupen de la gestión de los asuntos públicos, mientras los ciudadanos, desentendidos así de los asuntos públicos, encuentren la libertad en el disfrute de su vida privada y en la preservación de las restricciones externas. 
Barber se enfrenta diametralmente a esta forma de comprender la libertad, y, siguiendo las tesis rousseaunianas, dirá que no cabe en absoluto libertad en los ciudadanos sin una participación directa en la decisión de los asuntos que afectan a sus vidas a través de la deliberación y acción comunes, pues «la voluntad común, que depende del debate y la visión comunes, no puede ser representada». ${ }^{15}$

En la democracia blanda, la política la hacen los políticos, los expertos, no los ciudadanos. Esta idea queda nítidamente plasmada en una afirmación de Schumpeter en su obra Capitalismo, socialismo y democracia, donde dice que «la democracia es el gobierno del político». ${ }^{16}$ En esta forma de gobierno los ciudadanos encuentran reducidas sus funciones a una meramente pasiva elección de representantes. Ésta es la idea de democracia que articula para Barber la democracia blanda y es contra la que él lucha, tomando como base claramente las ideas de Rousseau.

Sin embargo, hemos de advertir que este rechazo de la representación y la propuesta de la participación directa lo lleva a cabo Barber en el marco de un discurso caracterizado precisamente por los elementos que dice combatir: la oposición y el antagonismo. Si nos damos cuenta, para este autor la democracia, o es blanda o es fuerte; o se produce la deliberación o la negociación; o agregación o transformación de preferencias; y más concretamente, en el tema que nos ocupa, si gobiernan los políticos, no pueden hacerlo los ciudadanos; o gobiernan unos, o los otros, no cabe aquí una posición intermedia. Los políticos no gobiernan por el bien común y los ciudadanos no necesitan representantes. Como vemos, reina la oposición. Ésta es una situación paradójica a la que lleva el discurso de Barber, quien pretendiendo superar la oposición propia del modelo liberal, la ha interiorizado hasta hacerla propia.
Por su parte, los defensores del modelo del «gobierno participativo empoderado», como Fung y Wright, entre otros, desarrollan un planteamiento aparentemente muy similar al de Barber. Parecen querer decir que la idea común de democracia significa una participación directa y activa por parte de los ciudadanos, y un control popular de las decisiones colectivas, mientras que el sistema representativo actual nos ha llevado a otra cosa bien distinta: un sistema regido por burócratas que no miran por el bien común ni permiten el desarrollo de los valores democráticos, como la libertad o la justicia social. Por ello, debe llevarse a cabo una redefinición de las instituciones democráticas que potencien la participación de la ciudadanía a partir de unas esferas locales como consejos vecinales, y dicha transformación para estos autores debería venir de la mano de los partidos de izquierda.

Sin embargo, y a diferencia de Barber, en lugar de ofrecer tanto un modelo teórico como la forma de su aplicación, lo que hacen es exponer ciertos casos empíricos en los que se ha procedido a esa transformación de las instituciones y después intentan sacar unos denominadores comunes. Aquí no podemos analizar caso por caso, pero sí querría señalar los elementos compartidos por todos ellos.

El primero es la participación directa de los ciudadanos. Éste es el elemento clave, o mejor dicho, radical. ¿Qué mejor modo de solucionar los problemas que permitiendo a los afectados aportar soluciones y gestionar los asuntos, en lugar de recurrir a un aparato burocrático lento y alejado de la situación real? Al proyecto del gobierno participativo late un espíritu claro: quien mejor puede solucionar un problema es quien lo padece. Esto no quiere decir que el aparato burocrático y de expertos quede anulado; se mantiene, pero en todo caso tendrá un pa- 
pel de mero asistente en la toma de decisiones de los ciudadanos, sin un poder decisorio.

Nos encontramos así con un traslado de los órganos de decisión de las jerarquías burocráticas centralizadas al nivel local, como por ejemplo, las asambleas vecinales. Esto no implica, sin embargo, que el poder político quede atomizado en mónadas sin conexión. Para estos autores, existiría un órgano central que organizaría los distintos grupos locales de decisión y reforzaría la calidad de la deliberación llevada a cabo en ellos. Ello lo hará distribuyendo recursos y solucionando problemas que cada unidad local por sí sola es incapaz de hacer. Con ello, en realidad, el gobierno participativo se queda a medio camino entre el sistema centralista y el plenamente descentralizado.

En segundo lugar, tenemos una orientación práctica. La política está hecha para resolver cuestiones prácticas que afectan directamente a los ciudadanos: las escuelas, la seguridad o la gestión de recursos. Esto hace que los encargados de resolverlas (los mismos ciudadanos) no compitan por cuestiones de poder con los otros, sino que se sientan más comprometidos con el bien común.

Y tercero y último: la deliberación. Este elemento forma una tríada fundamental en la democracia deliberativa con otros dos: la participación y la inclusión. El proceso de toma de decisiones entre los afectados será la deliberación. Cada cual intenta convencer a los otros mediante razones aceptables por todos sobre la conveniencia de su propuesta. Estos autores entienden también que las personas son razonables y que desean el bien común y no satisfacer sus intereses particulares. Esta deliberación es necesaria para formar las propias propuestas, ya que, frente al modelo pluralista, las personas no tienen tampoco preferencias fijas.
Del modelo del gobierno participativo debemos extraer tres conclusiones claves que lo alejarán de la propuesta de Barber: en primer lugar, nos encontramos con casos prácticos de los que se extrae no una teoría completa sino a lo sumo algunas ideas intuitivas, como pudiera ser lo beneficioso que resulta dar a los ciudadanos poder de decisión. Es decir, se acude a ejemplos concretos de lo que significa llevar el poder a los ciudadanos, pero como señalan Fung y Wright, eso no supone que se deban tomar esos casos como modelos que exportar a cualquier situación, como si fuera una teoría deductiva. ${ }^{17}$ En cambio, Barber proponía una política, la democracia fuerte, lista para ser aplicada allá donde se diera la democracia blanda.

La segunda diferencia está en que el gobierno participativo no lleva a cabo una atomización del poder en los grupos locales, sino más bien un escalonamiento del mismo. Es decir, deja de estar todo centralizado en los aparatos burócratas y ahora en su mayor parte pasa a los ciudadanos. En cambio, Barber repite constantemente que la política deben hacerla los ciudadanos, y sólo cuando ello no sea posible, por el elevado número de personas que deban participar, puede recurrirse a la representación. Ésta es para Barber anecdótica, casual, no un elemento más del sistema. Ahora bien, esto no significa que para el gobierno participativo la participación no sea directa; claro que lo es, sólo que se compagina la participación directa con una supervisión del sistema participativo mediante un órgano centralizado que mejore epistémicamente el proceso de deliberación directa. Se trata el órgano central de un elemento más, aunque claramente secundario, no como en Barber, que parece ser casual, puede darse o no. La diferencia entre Barber y los partidarios del gobierno participativo está en que para Barber deben gobernar 
los ciudadanos directamente, y cuando ello no sea posible, los encargados de hacerlo son unos representantes. En cambio, para los otros, los encargados de hacer política son siempre los ciudadanos, y el poder central es un elemento más del sistema, supervisor, pero no un sustituto del poder local. Para Barber el poder sólo puede estar en un nivel: o entre los ciudadanos o en los representantes, mientras que para los otros el poder político se distribuye entre las distintas esferas.

La tercera diferencia consiste en que el planteamiento de estos autores rompe con el esquema dicotómico de Barber: la participación directa no se opone a la representación. Frente a Barber, Fung no dice que sólo deban resolver las cuestiones los ciudadanos y que el recurso a la representación sea esporádico y para cuestiones concretas. Más bien son sistemas complementarios: puede haber una participación directa de los ciudadanos en los asuntos públicos gracias a la presencia de un nivel superior que supervisa y regula dicha participación. En los ejemplos citados por los autores del gobierno participativo, como el de Porto Alegre, el de Kerala o las escuelas de Chicago, no desaparece el nivel superior. No se trata de sustituir uno por el otro, porque no se oponen antagónicamente. No ven uno como bueno y otro como perverso, sino que el nivel local necesita al superior para funcionar adecuadamente.

\section{Los partidarios del sistema representativo como un mal menor}

Como hemos podido observar, los partidarios de la participación directa son un grupo bien escaso dentro de los defensores de la democracia deliberativa. En una posición cercana a la de este grupo encontramos la de aquellos que aceptan el sistema representativo, pero sólo como un mal menor, ante la imposibilidad de realizar una participación efectiva de to- dos los ciudadanos en el foro público. En este segundo grupo encontramos sólo a un autor, Carlos Santiago Nino. Él comparte con los defensores de la participación directa un elemento clave: el valor epistémico de la democracia reside en la participación, no meramente en la deliberación. Si partimos de la consideración de que el valor epistémico aumenta si participa un mayor número de personas, está claro que la representación contribuirá a restar dicho valor epistémico, por lo que no será vista con buenos ojos. De ahí que el sistema político debe ser lo más inclusivo posible, si quiere conservar su valor epistémico. ${ }^{18}$

Pero sin embargo, Nino es consciente de las condiciones que envuelven nuestras sociedades, por lo que entiende la imposibilidad de llevar a cabo un proyecto tan radical como la democracia fuerte de Barber. Comprende que en la actualidad se necesita de la representación, por varias razones: en primer lugar, por las limitaciones de tiempo y experiencia que tienen los ciudadanos para poder participar. También son desiguales las condiciones de poder de los ciudadanos. Pero también, porque entiende que la mediación de los representantes puede hacer que se delibere con unos conocimientos más técnicos sobre los asuntos que el ciudadano medio no posee. ${ }^{19} \mathrm{En}$ todo caso, el recurso a la representación debe entenderse como un mal menor ante la imposibilidad de que participen todos. A pesar de lo que hemos dicho, lo importante para Nino no es que se pueda deliberar mejor si el número de participantes es limitado. Al contrario, el valor epistémico le viene a la deliberación por una mayor inclusión. En consecuencia, para él las instituciones representativas no realizan el valor epistémico de la democracia. ${ }^{20}$

Por esa razón, de que no se den las condiciones para que participen todos no 
se sigue que debamos conformarnos con que eso siga siendo así. Resulta imperativo el tratar de establecer formas de democracia directa. Ahora bien, como señala también Mansbridge, no todas las formas de participación directa otorgan el mismo valor epistémico a la democracia. Así, para Nino los formatos como el referéndum o el plebiscito carecen de dicho valor. A pesar de que en ellos se facilita una expresión directa de las opiniones y de que pueden participar todos los ciudadanos, no se produce una deliberación genuina, por lo que su calidad epistémica es mínima.

Por ello, la democracia directa que propone Nino no es meramente pluralista, sino que requiere del recurso a la deliberación para alcanzar su valor epistémico y la tendencia a la imparcialidad. Esta deliberación es de la que se carece según Nino en los sistemas representativos. Así podemos ver cómo aunque este autor enfatiza el papel de la participación sobre el de la deliberación, ello no supone que deje a ésta en un completo segundo plano. Al contrario, la participación debe tener como principal elemento la deliberación, como entiende el resto de autores esta teoría de la democracia, ya que de lo contrario la propuesta participativa podría quedar en una vuelta al modelo antagonista por la forma del voto directo y secreto.

Para Nino la democracia directa se lograría a través de procesos de descentralización política que generaría unidades políticas autosuficientes capaces de desarrollar un proceso de discusión cara a cara, al modo como se ha dado en los town meetings de EE.UU. y en los cantones suizos. Así los ciudadanos podrían debatir en asambleas populares los asuntos que les afectan como la sanidad o educación. Se trata así de que todos los ciudadanos puedan participar y decir lo que piensan para poder tomar una deci- sión correcta. Como podemos ver, el fin es lograr la participación directa. Pero mientras no se den las condiciones para el cambio, es necesario el recurso a la representación.

\section{Los detractores de la participación directa}

En un tercer y último grupo hemos de situar a aquellos autores que se muestran contrarios a la participación directa de los ciudadanos en la política. Éstos defienden el sistema representativo, pero no por considerarlo un mal menor ante la imposibilidad de lograr una participación de todos los ciudadanos, sino porque conciben la representación como el único modo de mantener el valor epistémico de la deliberación. Aquí encontramos a la mayoría de autores de la democracia deliberativa, desde Habermas a Bohman, pasando por Cohen, Richardson, Christiano, Fishkin, Mansbridge, Gutmann y Thompson o Dryzek. Para estos autores, el valor epistémico no reside precisamente en la participación, sino más bien en la deliberación.

Como podemos comprobar, existe un hiato de trascendental importancia entre los demócratas deliberativos: unos ponen el acento en lograr una máxima inclusión en el proceso de toma de decisiones a la vez que entienden dicho proceso como deliberativo. Mientras, el resto parece encontrarse ante un inconveniente: entienden que enfatizar la participación directa supone devaluar el proceso deliberativo, y que la única manera de deliberar en condiciones debe ser sacrificando la participación de todos. Ésta es una problemática presente para aquellos autores de la democracia deliberativa que han optado por salvar las condiciones que permitan una deliberación exitosa y que entienden una amplia participación como perjudicial para la misma. Ello debe hacerse 
a costa de perder el ideal de la participación directa.

Entre los autores de la democracia deliberativa son tres los que más han alertado sobre la misma: Bohman, Goodin y sobre todo Fishkin. ${ }^{21}$ Como muy acertadamente señala este último, el dilema entre deliberación e inclusión surge al pretender extrapolar el sistema de democracia cara a cara ateniense al ámbito del Estado-nación imperante en la actualidad. Es decir, en la antigua Grecia el modo de participación política era a la vez inclusivo y deliberativo: todos los considerados entonces ciudadanos podían participar en el ágora para tomar las decisiones que incumbían al conjunto de la pólis. A la vez, esa participación no se llevaba a cabo de una forma meramente agregativa, sino mediante la deliberación comunitaria. Sin embargo, en la modernidad el gran tamaño y población de nuestras sociedades ha producido una ruptura con el modelo antiguo. Ahora, si se quería dar igual poder político a todos los ciudadanos debía renunciarse al elemento de la deliberación, ya que es evidente que decenas o cientos de miles de personas no pueden reunirse para deliberar. De este modo, si se quiere mantener la deliberación en la toma de decisiones sólo cabe una salida: el recurso a la representación, con lo cual se sacrifica el elemento de la participación, pues ya no son los ciudadanos los que determinan el desarrollo del proceso político, sino sólo unos pocos, los representantes elegidos.

Para Fishkin, los movimientos que se han dado en la actualidad hacia la democracia directa han ido en la línea de salvar la igualdad política para dar un igual poder a todos, pero, eso sí, a costa de la deliberación. ${ }^{22}$ Los casos más evidentes son los plebiscitos y los referenda. Pero Fishkin entiende que la participación debe ir acompañada de deliberación si quiere ser realmente efectiva para solucionar los problemas de los ciudadanos. Y esto mismo es lo que propone conseguir con su idea de las encuestas deliberativas y el Día de la Deliberación, que expondré más adelante.

La razón de por qué los miembros de este último grupo encuentran una difícil complementación entre participación $\mathrm{y}$ deliberación se encuentra en el modo como entienden el proceso deliberativo. Para Fishkin, Mansbridge, Goodin o Habermas la deliberación es incompatible con una amplia participación porque siguen presos en los esquemas griegos. Todos ellos asimilan la participación deliberativa al modo de una reunión en el ágora entre todos los ciudadanos. Pero es obvio que ello es imposible en las sociedades a gran escala, en las que conviven millones de habitantes. Por ese motivo se hace tan necesario limitar el número de participantes en la deliberación. Éste es el motivo que, en mi opinión, lleva a Habermas a escindir el proceso de formación de la opinión pública del de la toma de decisiones y el que lleva a Mansbridge a admitir la necesidad de un marco institucional de tipo antagonista en las sociedades actuales. Por esa razón también, como el modelo griego es inviable tal cual, se requiere limitar el número de personas que tomen las decisiones, y de ahí el recurso a la representación.

En cambio para los autores del primer grupo (Barber y los defensores del gobierno participativo), y para Nino, el número de participantes no es un problema, porque ellos no entienden la participación al modo ateniense, sino como una descentralización política, como sucede en Porto Alegre con las asambleas vecinales. Entre los autores de los dos primeros grupos (el de participación directa y el que ve la representación entendida como un mal menor) no se produce el choque entre participación y deliberación porque la participación no se entiende 
como un ágora gigante, sino como un mosaico de asambleas participativas coordinadas desde arriba por un sistema central. En cambio, por ejemplo, en la red comunicativa de la sociedad civil dentro de la teoría habermasiana no se produce ningún tipo de descentralización política. Ésta es para mí la diferencia esencial entre el tercer grupo y los dos anteriores que nos permite explicar también sendos enfoques en la concepción epistémica de la democracia deliberativa. Ella hace que para unos autores incrementar el número de participantes sea contraproducente y reste valor epistémico mientras que para los otros sea al contrario, cuantos más participantes intervengan, más intereses serán expuestos y mayor conocimiento se tendrá de la situación para así tomar decisiones más adecuadas.

Sin embargo, también es cierto que no todos los autores entienden de la misma manera el modo como articular el recurso a la representación. Las distintas propuestas pueden ser clasificadas en los siguientes grupos:

1) Por un lado, tendríamos a aquellos que consideran que la deliberación sobre la toma de decisiones políticas debe limitarse a los foros institucionales actuales y no proponen unos foros alternativos más próximos a los ciudadanos que les hagan más partícipes del gobierno. Es decir, se trata de reducir el número de personas que participen en la deliberación, en este caso, los representantes políticos. Aquí encontramos a Cohen, Mansbridge, Richardson, Christiano y Gutmann y Thompson. El primero entiende que la implantación del ideal deliberativo conllevaría la creación de foros de deliberación en los que los ciudadanos puedan realizar sus propuestas sobre el contenido de la agenda política. No obstante, esto lo ve imposible ante la existencia de desigualdades materiales, las cuales impiden que todos puedan participar en igualdad de condiciones. De ahí que Cohen defienda la existencia de órganos representativos como los partidos políticos, que puedan defender mejor los intereses de los menos aventajados y superar las desigualdades en las arenas deliberativas. ${ }^{23}$

Por lo que respecta a Mansbridge, ella también se muestra reacia a la participación directa de los ciudadanos en la política. Así lo manifiesta en Beyond adversary democracy, al decir que las democracias a gran escala necesitan de una democracia antagonista. ${ }^{24}$ Del mismo modo, en un artículo posterior titulado «Rethinking Representation», afirma que no debemos pensar en el sistema representativo como un mal necesario ante la imposibilidad de llevar a cabo la participación directa de los ciudadanos en la gestión de los asuntos públicos. El sistema representativo tiene un valor por sí mismo, que debe ser reconocido. ${ }^{25}$

Finalmente, respecto a Gutmann y Thompson, en su obra conjunta Democracy and disagreement llegan a afirmar que la representación en la democracia deliberativa no es sólo necesaria, sino incluso deseable. ${ }^{26}$ Éstas son sus palabras: «El número de personas que pueden mantener una conversación en un mismo momento, permitiéndose sólo argumentos morales, es limitado.» ${ }^{27}$ Esta afirmación es un reflejo del dilema al que me refería antes entre deliberación y participación.

Richardson y Christiano se pueden incluir dentro de este grupo. Para ellos también el valor epistémico de la democracia reside en la deliberación. Así por ejemplo dice Richardson en Democratic autonomy que «las asambleas necesitan ser lo bastante pequeñas para que los representantes puedan deliberar juntos y lo bastante grandes para que las principales visiones de los ciudadanos puedan ser justamente representadas». ${ }^{28}$ Pero am- 
bos autores se diferencian del resto en que aquello que se representa no son los intereses o preferencias de los ciudadanos, sino más bien las visiones colectivas de los sujetos. De lo contrario, entienden, el proceso político quedaría cosificado, ya que los intereses y preferencias se entienden como fijos, cuando realmente las visiones colectivas se pueden modelar.

Esta concepción de la representación se muestra de una forma clara en la idea de Christiano de la igualdad cualitativa. ${ }^{29}$ Para Christiano igualdad política no debe entenderse meramente como la igualdad entre ciudadanos. Debe ir más allá para ser una igualdad cualitativa, no entre personas, sino entre concepciones. Así por ejemplo, para este autor los recursos no deberían distribuirse de una forma igualitaria entre individuos, sino entre concepciones del bien. Es decir, que no reciba más recursos o disponga de más tiempo en los medios de comunicación una Iglesia por tener más miembros que las otras.

Es más, Richardson encuentra contradictoria la participación directa de los ciudadanos. Según él, el populismo radical, según el cual la gente debe decidir todo, es irrealizable porque cae en un círculo vicioso: la voluntad del pueblo se realiza mediante un procedimiento democrático; pero a su vez dicho procedimiento se debe determinar por la voluntad del pueblo si es que éste debe determinar todo mediante su voluntad, pero también este movimiento debe realizarse por un procedimiento democrático que fije quién tiene derecho al voto. Es decir, el pueblo debe establecer los procedimientos por los que se determine esa misma voluntad del pueblo, lo cual es absurdo. 30

2) Otra respuesta a estos problemas de complejidad ha sido separar la deliberación pública del proceso de toma de decisiones en las instituciones. Éste es el punto de vista de Habermas y sus seguidores, como Seyla Benhabib, John Dryzek y James Bohman.

El motivo por el que Habermas rehúsa a defender una participación directa consiste esencialmente en el hecho de la complejidad social. En este sentido, en su propuesta de la Política Deliberativa, desarrollada en Facticidad y validez y en otros artículos más recientes, ${ }^{31}$ distingue la formación de la opinión en la esfera pública de la esfera dedicada a la formación de la voluntad en las instituciones políticas. Habermas apuesta por que la opinión pública pueda influir en la voluntad generada en los foros institucionales. Pero no contempla una participación directa de los ciudadanos en la formación de la voluntad. Nos encontramos con dos ámbitos separados: en la esfera pública, formada por unas redes de comunicación sin un sujeto determinado, las asociaciones y grupos de interés, formadoras de la opinión, se comportan al modo de una serie de sensores que recogen las preocupaciones de los ciudadanos y las transmiten a la esfera institucional para que los representantes políticos procuren su solución. No se trata sólo de que la opinión pública controle el ejercicio del poder político, sino de que también lo programe, ya que los elementos de la opinión pública, como asociaciones o medios de comunicación generan opiniones de gran influencia social.

Así Habermas distingue entre esa esfera pública informal y el Parlamento, lo que le lleva a distinguir el poder de decidir de la influencia en la deliberación institucional. Aunque los ciudadanos pueden decidir ocasionalmente (elecciones y referéndum), la sociedad en conjunto se limita a influir en la deliberación, no toma parte del proceso de toma de decisiones. La participación política de los ciudadanos se encuentra así a un doble nivel: por un lado, de una forma institucionalizada, me- 
diante la elección de representantes en comicios electorales; y de una forma informal, mediante la participación de los sujetos en las asociaciones y grupos de la sociedad civil formadores de opinión.

Este planteamiento supondría, al menos en parte, dar la razón a los teóricos de la concepción elitista de la democracia. Para ellos, recordemos, la función de los ciudadanos era meramente la de elegir a los representantes, que eran los únicos legitimados para tomar decisiones. Pero la Etica Discursiva reserva una función particular a los ciudadanos, más allá de la mera elección de los políticos, la de favorecer intereses universalizables mediante la participación en el foro público para que los políticos tengan que tomarlos en cuenta, como sucedía con los sabios ilustrados. ${ }^{32}$

En una posición similar a la habermasiana se mueve Bohman, aunque éste se decanta por una transformación institucional que permita una mayor participación de los ciudadanos en el proceso de toma de decisiones, a través de una división del trabajo en la deliberación y la creación de nuevos públicos. Entiende Bohman que algunos asuntos requerirán de la deliberación entre todos los ciudadanos, mientras que otros sólo su tratamiento en los foros de representación. ${ }^{33}$ Ahora bien, esto no quiere decir que todos los ciudadanos puedan reunirse para deliberar sobre esos temas. Ésta es una posibilidad que Bohman rechaza repetidas veces, dado el hecho de la complejidad social. Más bien de lo que se trata es de que las instituciones permanezcan receptivas a las influencias que reciban de la esfera pública, siendo ésta más plural que en Habermas. Para Bohman, los distintos públicos poseen una gran influencia para la reforma institucional. ${ }^{34}$ Incluso habla de una «razón pública plural». ${ }^{35}$

3) La tercera alternativa es similar a la elección de representantes de los ciu- dadanos, aunque en este caso, la diferencia está en que los elegidos no son candidatos de partidos, sino unos ciudadanos al azar para que deliberen en representación de todos, terminando dicha deliberación mediante una votación secreta. Esta alternativa viene representada sobre todo por la denominada Encuesta Deliberativa (Deliberative Poll) o Día de la Deliberación, defendida por Fishkin y Ackerman, y ha sido aplaudida por otros teóricos de la democracia. ${ }^{36} \mathrm{Al}$ elegir a las personas al azar y habiéndoseles suministrado información relativa al tema que será abordado, se trata de que el conjunto elegido de ciudadanos representen un microcosmos del pueblo y por la deliberación decidirán lo que hubieran decidido entre todos si todos hubieran podido deliberar.

No obstante, si nos damos cuenta, el Día de la Deliberación sigue preso del modelo de democracia cara a cara ateniense y pretende implantar dicho modelo en la sociedad actual. El espíritu de esta propuesta es: como no pueden deliberar todos juntos, elijamos a un conjunto reducido para que lo hagan por el resto en una forma de igualdad política. De esta manera se podrá saber lo que habría decidido la sociedad en su conjunto, compuesta por ciudadanos bien informados y comprometidos, si hubiera podido deliberar. Esta es también la única forma posible de escapar al dilema al que se enfrenta Fishkin: la participación directa en la sociedad a gran escala se hace a costa de la deliberación, pero el sistema representativo liberal, aun permitiendo la deliberación, viola la igualdad política, al estar sometido a la corrupción y el soborno.

Sin embargo, en mi opinión, el aspecto más criticable es el recurso al voto secreto. ¿Qué garantías existen de que las personas al final votarán teniendo en cuenta los argumentos escuchados y no por sus propios intereses? Pero sobre 
todo, ¿por qué tanto miedo al voto público si se piensa que los ciudadanos son razonables y que quieren el bien común? Esto es algo que no parece encajar en el proyecto del Día de la Deliberación, que parecía querer llevarnos a una situación casi idílica de comprensión mutua. No es suficiente decir que se recurre al voto secreto para que los ciudadanos no se vean influidos por la presión social, pues si eso es así, ¿de qué sirve entonces la deliberación? ¿No sería ésta en sí misma una forma de presión que impide que los ciudadanos voten según lo que inicialmente creen? Además, si se trata de que las personas escuchen a los otros y cambien su mente, y si de hecho eso sucede, parece difícil creer que los ciudadanos elegidos puedan representar adecuadamente al conjunto de la sociedad. ${ }^{37}$

Ahora bien, que la mayoría de autores de la democracia deliberativa crean oportuno el sistema representativo frente a las formas de participación directa no significa que sus planteamientos caigan en el derrotismo frente al sistema liberal imperante. Como he mostrado a lo largo de estas páginas, la democracia deliberativa no se caracteriza por pretender la participación directa de todos los ciudadanos en la cosa pública. Más bien es por su propósito de conseguir el compromiso de los ciudadanos por el bien común, frente al sistema liberal, en el que primaba la satisfacción de intereses egoístas. Por ese motivo, el modo de comprender la legitimidad del sistema representativo debe ser también diferente a como sucedía en el modelo liberal. En el liberalismo de corte elitista se entiende que los representantes políticos están legitimados si su actuación se corresponde con los intereses de sus representados. De ahí que Schumpeter entendiera la democracia como el sistema político en el que los ciudadanos cambian de gobernantes cuando creen que éstos no satisfacen sus intere- ses. Pero si nos damos cuenta, este criterio es del todo agregativo: son los intereses particulares de los votantes los que determinan la legitimidad de la actuación de los representantes. Cuando un político no satisface los intereses de quienes le eligieron, dejará de estar legitimado.

Por ello, la democracia deliberativa propone un modo alternativo de entender la representación y la misma idea de legitimidad democrática. ${ }^{38}$ Así proponen que sea una deliberación entre los ciudadanos y otra entre los ciudadanos y sus representantes las que determinen si los representantes están actuando correctamente y si cumplen con su programa electoral. Esto implica que la representación no debe ser pensada al modo del fideicomiso, pues el ciudadano no se desentiende de la labor que realiza el representante ni éste deja de rendir cuentas en el período transcurrido entre las elecciones, debido a la deliberación continuada entre ciudadanos y representantes. ${ }^{39}$

\section{Conclusión}

El examen realizado de la participación política dentro de la democracia deliberativa pone de manifiesto la gran heterogeneidad de propuestas que abarca esta teoría de la democracia, lejos, por tanto, de los tópicos extendidos en el ámbito teórico referentes a la apuesta de este modelo de democracia por una reforma sustancial del sistema político vigente basado en la representación. En este sentido, por lo que hace al desarrollo histórico de esta teoría, debemos concluir que si bien ésta en un principio fue pensada como un modelo que reemplazara al sistema liberal imperante, como hizo, por ejemplo, Barber con su proyecto de democracia fuerte, en sus desarrollos posteriores ha asimilado las condiciones de complejidad social como inherentes a la vida política contemporánea que imposibilitan una 
participación más directa de los ciudadanos en la gestión de los asuntos públicos.

A la luz de las diversas propuestas estudiadas, la corriente que apuesta por la representación resulta a mi parecer más adecuada para llevar a cabo las reformas que el sistema liberal necesita. Por el contrario, la defensa de una participación directa en la gestión de los asuntos públicos por parte de los ciudadanos se muestra a todas luces una iniciativa demasiado ambiciosa. Así, el proyecto de la democracia fuerte de Barber debe ser descartado ya que es irrealizable en nuestras sociedades. La reforma institucional que propone resulta demasiado compleja para poder ser llevada a la práctica más allá de la toma de determinadas decisiones a nivel local, pues demanda una gran cantidad de tiempo a la ciudadanía, cuando realmente éste es un elemento escaso del que el ciudadano medio no dispone. Por lo que hace al modelo del gobierno participativo de Fung sucede algo similar. Todas esas propuestas se refieren a contextos y medidas concretas que no pretenden abarcar el conjunto del marco institucional y político de nuestras sociedades de masas.

Se hace, por tanto, necesario el recurso al sistema representativo. No obstante, como dijimos, este hecho no debe conducir al derrotismo. Al contrario, la democracia deliberativa tiene como objetivo reformar el sistema representativo liberal para hacerlo más deliberativo y para que en él los ciudadanos no participen con el fin de satisfacer sus intereses individuales, sino con vistas al logro del bien común. De ahí que mantener el sistema representativo no deba interpretarse como un freno a las reformas que el sistema político necesita. Más bien al contrario, apostar por la representación en la democracia deliberativa significa impulsar las reformas que la democracia necesita y que sólo mediante la representación política podrán llevarse a la práctica. Como vimos anteriormente, para autores como Habermas, Gutmann y Thompson o Fishkin introducir la participación directa dificulta la toma deliberativa de decisiones. Por ello desde esta corriente de la democracia deliberativa se pretende rehabilitar la concepción de la representación política, desechando los elementos negativos fomentados por el sistema liberal y potenciando otros nuevos, como la deliberación, el logro del bien común o la participación activa de los ciudadanos.

De las diversas propuestas realizadas para dirigir el sistema representativo actual hacia un modelo más participativo, creo que la más interesante es sin duda la conocida «democracia radical», elaborada por Adela Cortina sobre la base de la Ética del Discurso de Apel y Habermas. A juicio de Cortina, el modo de revitalizar la vida democrática no puede pasar hoy por pretender una participación directa al estilo de la democracia fuerte, ya que no es posible que intervengan todos los ciudadanos todo el tiempo para la toma de decisiones. El ideal participativo debe promover que los ciudadanos participen activamente, no en la toma de decisiones políticas, como lo entiende Barber, sino en los grupos de la sociedad civil a los que pertenecen, como la familia, las iglesias o los movimientos sociales. ${ }^{40}$ Dado que el sistema político está dominado por la lógica del autointerés de tal forma que su función ha quedado reducida a lograr mantener el equilibrio entre intereses en conflicto, se hace perentorio que surja un nuevo sujeto que actúe de referente moral de la sociedad, y este sujeto lo representa la sociedad civil. Es en ella donde se forjan los sentimientos de solidaridad y de compromiso con el bien común que pueden hacer suyos los ciudadanos. ${ }^{41}$ Como afirma Cortina, la sociedad civil «es indispensable para construir cualquier edificio político medianamente sólido». ${ }^{42}$ 
La sociedad civil es fundamental para devolver a los ciudadanos el compromiso con los valores cívicos que se plasmarán también en su participación política. Pero también lo es para recoger y trasladar a la esfera institucional los problemas que afectan a la ciudadanía, procurando su solución en el Parlamento. No obstante, esto sólo será posible si se lleva a cabo el necesario control de la acción de los gobernantes en el ámbito de la opinión pública. Para ello es necesario el requerimiento a los políticos de que ofrezcan justificaciones públicas de las decisiones tomadas. Sólo así las decisiones de los políticos quedarán legitimadas ante la opinión pública en el marco de las sociedades democráticas.

Como afirma Cortina, si la degeneración del sistema democrático ha veni- do por las malas prácticas de las élites políticas, su revitalización vendrá por la articulación de una sociedad civil fuerte que devuelva a los ciudadanos el compromiso cívico. ${ }^{43}$ De esta manera, podrá la democracia deliberativa lograr desplegarse en el ámbito político actual y alcanzar sus objetivos de regeneración y transformación política que permitan articular una vida mejor para todos en nuestras sociedades democráticas. Por tanto, la solución más eficaz para regenerar la vida política no pasa por sustituir el actual modelo político por otro antagónico, sino por el acendramiento del sistema representativo gracias a la labor de los ciudadanos comprometidos desde la sociedad civil en el marco de una democracia radical.
* Este trabajo se enmarca dentro del proyecto de investigación consolidado «El reconocimiento recíproco como base de una bioética intercultural» (FFI2008-06133/FISO), financiado por el Ministerio de Ciencia e Innovación.

1 Crozier, M., Huntington, S. y Watanuki, J. The crisis of democracy. Report on the governability of democracies to the Trilateral Commission. New York: New York University Press, 1975.

2 Mansbridge, J. Beyond adversary democracy. Chicago: University of Chicago Press, 1983.

3 Bohman, J. «Survey article: The coming of age of deliberative democracy», Journal of Political Philosophy, vol. 6, 1998, pp. 400-425.

${ }^{4}$ Estlund, D. «Who is afraid of Deliberative Democracy? On the Strategic/Deliberative dichotomy in recent constitutional jurisprudence», Texas Law Review, vol. 71, 1992, p. 1444.

5 Cortina, A. «Democracia deliberativa», Contrastes. Suplemento, núm. 2, 2007, p. 154.

6 Schumpeter, J. A. Capitalismo, socialismo y democracia. Barcelona: Folio, p. 333

7 Richardson, H. «Democratic intentions», en James Bohman y William Rehg (eds.), Deliberative democracy. Essays on reason and politics: Cambridge: The MIT Press, 1997, p. 350.

8 Bohman, J. Public deliberation. Massachussets: The MIT Press, 1996, p. 27.
9 Benhabib, S. «Deliberative rationality and models of democratic legitimacy», Constellations, vol. 1, núm. 1, 1994, p. 32.

10 Fung, A. y Wright, E. O. Deepening democracy. New York: Verso, 2003.

11 Barber, B. Democracia fuerte. Córdoba: Almazara, 2004, p. 330; Fung, A. y Wright, E. O. op. cit., p. 23; Nino, C. S. La constitución de la democracia deliberativa. Barcelona: Gedisa, 1997, p. 185

12 De hecho, hemos de advertir que el número de participantes no determina por sí sólo el valor epistémico del proceso. A lo sumo puede ser un elemento que aumente o reste dicho valor en la medidas en que se entienda que el mayor o menor número de participantes haga un proceso deliberativo más o menos adecuado.

13 No hemos de olvidar que la constricción del tiempo en la deliberación ya era advertida por Rawls en su Teoría de la justicia con su concepto de «racionalidad deliberativa».

14 Dryzek, J. «Legitimacy and economy in deliberative democracy», Political Theory, vol. 29, núm. 5, p. 652 .
15 Barber, B. op. cit., p. 330.
16 Schumpeter, J. op. cit., p. 362.
17 Fung, A. y Wright, E. op. cit., p. 39.
18 Nino, C. S. op. cit., pp. 185-6.
19 Ibid., p. 184.
20 Ibid., p. 205. 
21 Bohman, J. op. cit., p. 178; cfr. Goodin, R. Reflective democracy. Oxford: Oxford University Press, 2003, pp. 3-5; cfr. Fishkin, J. Democracia y deliberación. Barcelona: Ariel, 1995. Esta obra de Fishkin constituye una reflexión sobre la aporía entre participación y deliberación y de cómo su propuesta de las Encuestas de Opinión (de la que hablaremos después) representa una solución apropiada a la misma.

22 Fishkin, J. op. cit., p. 137.

23 Cohen, J. «Deliberation and democratic legitimacy», en James Bohman y William Rehg (eds.). Deliberative democracy. Essays on reason and politics. Cambridge: The MIT Press, 1997, p. 85.

24 Mansbridge, J. op. cit., p. 13.

25 Mansbridge, J. «Rethinking Representation», en American Political Science Review, vol. 95, núm. 4, 2003, p. 515.

26 Gutmann, A. y Thompson, D. Democracy and disagreement. Harvard: Harvard University Press, 1996, pp. 128 y 131

27 Ibid., p. 131.

28 Richardson, H. Democratic autonomy. Public reasoning about the ends of policy. Oxford: Oxford University Press, 2002, p. 199.

29 Christiano, T. The rule of the many. Colorado: WestviewPress, 1996, pp. 91-93.

30 Richardson, H. op. cit., p. 67.

31 Habermas, J. Facticidad y validez. Madrid: Trotta, 1998, p. 436; Habermas, J. «Tres modelos normativos de democracia», en La inclusión del otro.
Estudios sobre teoría política. Barcelona: Paidós, 1998, pp. 231-246.

32 Cortina, A. Ética aplicada y democracia radical. Madrid: Tecnos, 2001, p. 121

33 Bohman, J. op. cit., p. 162.

34 Ibid., p. 177.

35 Otra propuesta realizada en el marco de la Ética Discursiva es la «democracia radical» de Adela Cortina. A ella nos referiremos más adelante, en las conclusiones.

36 Dahl, R. «On Deliberative Democracy», Dissent, núm. 44, 1991, pp. 54-58.

37 Goodin, R. op. cit., p. 174

38 Mansbridge, J. «Rethinking Representation», op. cit., p. 525.

39 Parkinson, J. «Legitimacy problems in Deliberative Democracy», Political Studies, vol. 51, 2003, p. 188.

40 Cortina, A. Ética aplicada y democracia radical, pp. 89-157.

41 Frente al enfoque habermasiano, de acuerdo a Cortina también formarían parte de esa sociedad civil las empresas, ya que sus actividades tienen unas implicaciones públicas que deben regirse por un sentido de la responsabilidad social y no sólo por el beneficio económico.

42 Cortina, A. «Ethica cordis», Isegoría. Revista de Filosofía Moral y Política, núm. 37, 2007, pp. 113-114.

43 Cortina, A. Ética aplicada y democracia radical, p. 151 